\title{
MzS Tools: GIS methods and tools for seismic microzonation mapping
}

\author{
Giuseppe Cosentino ${ }^{1, *}$, Francesco Pennica ${ }^{2}$, Emanuele Tarquini ${ }^{2}$, Giuseppe Cavuoto ${ }^{3}$ and Francesco Stigliano ${ }^{2}$
}

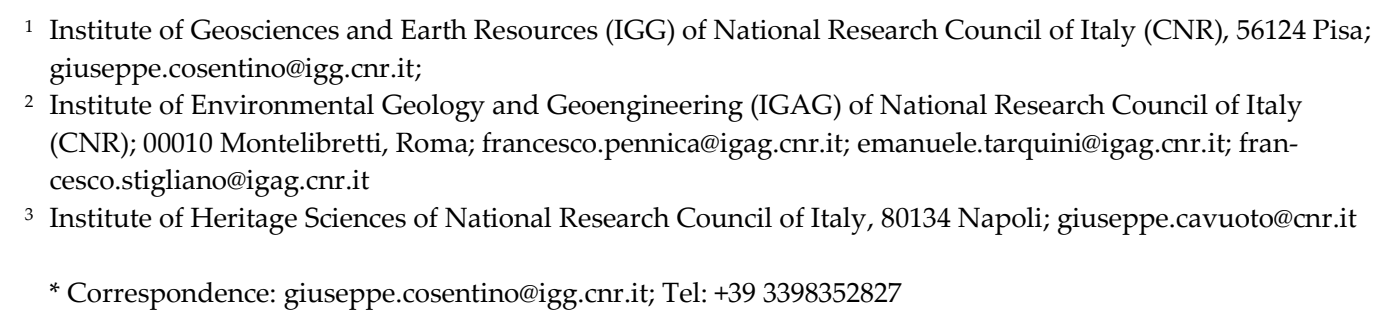

\begin{abstract}
MzSTools is a plugin for QGIS developed by the National Research Council (CNR) as part of the activities concerning the coordination of seismic microzonation studies in Italy. It train from the need to create a practical and easy-to-use tool to carry out seismic microzonation (SM) studies by producing standards compliant geographic database and maps, thus making them accurate, homogeneous and uniform for all municipalities in Italy. A geodatabase based on SQLite/SpatiaLite Relational Database Management System (RDBMS). It has been designed to collect and store data related to elements such as: geognostic surveys; bedrocks and cover terrains; superficial and buried geomorphological elements; tectonic-structural elements; elements of geological instability such as landslide zones, liquefaction zones and zones affected by active and capable faults; homogeneous microzones in seismic perspective, microzones characterized by a seismic amplification factor. The QGIS plugin provides tools such as data entry forms designed with Qt Designer; a QGIS project template with layers, symbol libraries and graphic styles; layouts for the SM Maps. MzSTools assembles in a single software environment a set of useful tools for those who work in. The plugin is open source, whose code hosted on the GitHub platform, and is published via the official QGIS plugins repository (https://plugins.qgis.org/plugins/MzSTools/).
\end{abstract}

Keywords: Geological surveys; Field mapping; Python; QGIS plugin; RDBMS; Seismic microzonation; SQLite-SpatiaLite Database.

\section{Introduction}

Earthquakes, landslides, subsidence, and floods are geological hazards that affect urban centres and are the cause of numerous human lives and huge economic losses. To reduce the impacts that geological hazards cause, international agencies address their policies to mitigation of natural hazards [15]. Earthquakes are one of the main natural disasters and many studies is aimed at mitigating the seismic risk. To achieve this goal, geological, geotechnical and geophysical data are analyzed and integrated to map zones, especially in urban areas, with homogeneous seismic behavior in case of a seismic event; these kinds of studies are called seismic microzonation. For some years, the data necessary for this kind of studies have been managed through a geographic information systems (GIS).

The GIS allow to manage data assigning geographic information, attributes and to produce new information through operations of spatial analysis on different kinds of data.

The first examples of seismic microzonation studies (SM) in urban areas carried out starting from geological and geotechnical data in a database, data interpolation and spatial analysis using tools available in the GIS software and finally fulfilment of microzonation maps. 
Some experiences of SM carried out based on a single hazardous parameter (e.g. VS30, natural period and response spectra) and interpolation of this kind produced thematic maps. The spatial distribution of these parameters has provided information on the scenario of site amplification in different parts of the city [7]. In some cases, the significance of the maps generated, with geological and geophysical data (e.g. fundamental period or liquefaction susceptibility) with respect to damage risk, was verified by a statistical regression analysis using statistical tools [5].

MS studies carried out, also, using automated methodologies GIS-aided. In this case, GIS was used only for locating the available borehole and for drawing digital contour maps, data processing performed externally to the GIS with a specific software. Some selected geological data along with engineering geological information processed in establishing the shear wave with depth to estimate as a final product, seismic ground surface response in the study area [11]. The GIS systems are also employed with integrated systems that consist of a DB with different kinds of information data and sub-modules that execute various functions (input, geostatistical 3D integration, real-time earthquake hazard assessment) to obtain earthquake hazard liquefaction assessment [6].

Identifying areas in the territory with a homogeneous seismic response in case of earthquake is the result of the analysis of different geological, geomorphological and geophysical factors.

For this reason, some SM carried out using the multicriteria decision analysis which, through the analytical hierarchy process (AHP) technique, assigned to factors (peak ground acceleration, geology, geomorphology, slope amplification factor, etc.) weights depending on its contribution to the seismic hazard and maps of susceptibility to seismic risk are produced $[2,3,4,8,10]$.

In Italy, after the earthquake in 2009, the "National Plan for Earthquake Prevention" was launched and in the law 77/2009 were assigned incentives to achieve seismic microzonation studies in all the cities with Peak ground acceleration (PGA) $>0.125$ g. SM studies have been regulated by technical documents drawn up by the Italian Civil Protection and foresee three levels of study. The first level identifies homogeneous areas in a seismic perspective on a purely geological basis [9], levels 2 and 3 quantify the seismic amplification with numerical analyses of local seismic response.

To provide recommendations on how to conduct SM studies in the three levels, Italian Civil Protection with the support of experts, defined a technical reference document, guidelines, and Standards. Cartographic Standards have been prepared ("Standards of representation and computer archiving"1) to obtain studies homogeneous in different cities. This document defined a data storage framework, maps symbology, data codes, maps to be created according to different levels of studies [14].

One of the critical steps in a SM studies is to realize maps according to the SM Standards. In fact, this step is subjected to inspection by a technical structure that checks the correspondence of what is present in the study to the cartographic Standards. In case of mistakes, the study is not validated and it is sent back to the geologist to rectify.

In this study, a specific tool was developed within the QGIS software with the aim of drawing thematic maps (MOPS map, survey map, geological-technical map, microzonation maps, etc.) and to archive geological, geotechnical and geophysical data in SM studies according to the provisions of Italian legislation.

To support geologists avoid mistakes in, assigning the codes to the expected elements in, archiving in the survey database in, fulfil maps respecting the topological rules (e.g. non-overlapping, adjacency without spaces between geological polygons), carried out MzS Tool .

This tool, downloadable as a QGIS plugin, allows to make SM maps and geological, geotechnical and geophysical databases according to technical documentation produced by the Italian National Civil Protection.

${ }^{1}$ Commissione tecnica per la microzonazione sismica MICROZONAZIONE SISMICA STANDARD DI RAPPRESENTAZIONE E ARCHIVIAZIONE INFORMATICA

Versione 4.2 Roma, dicembre 2020. https://www.centromicrozonazionesismica.it/it/download/summary/38-standardms-42/98-standardms-4-2 


\section{Materials and Methods}

The complexity of the mechanical and physical characteristics of the subsoil complicates the data archiving process as a function of the information to be analyzed and represented cartographically. To obtain a good result, the geological information needs a well-defined data structure, respecting a specific scheme that guarantees its integrity, consistency and graphic reproduction by means of standardized thematic maps.

The standardization of data storage and their cartographic representation facilitates the reading and comparison of results in different territorial backgrounds. The SM Standards contain the technical specifications for the preparation of the elements necessary to carry out the MS studies, listed below:

- the legends (symbols, colors, descriptions) and layout maps;

- The storage structure of alphanumeric data and geographic data;

- The structure of the study report.

The SM Standards do not explain the procedural aspects to be adopted for the implementation of SM studies, such as the use of specific software or data management and processing tools; the decisions concern the professionals of the studies. The basic requirements are that the data storage and maps, regardless of the software and tools used, comply with the MS Standards.

The software platform used for the development of the MS database and cartography tools was made on the open source and multiplatform QGIS software.

QGIS [12] is one of the most widely used and best known open source GIS software [13]; it features a huge number of capabilities ranging from data editing to geoprocessing, with support for all the main raster and vector data formats and online services such as WMS (Web Map Service) and WFS (Web Feature Service). These capabilities, great extensibility and ease of use, make QGIS an obvious choice for an open, integrated platform for GIS projects. Moreover, an open source software does not force users and institutions to acquire commercial licenses and to become dependent on a single vendor for products and services ("vendor lock-in").

The basic idea of the development of the plugin for QGIS "MzS Tools" was to organize, in a single dashboard, a complete set of software tools useful for SM studies, simplifying the procedures for creating projects and Maps of SM according to the SM Standards. QGIS allows you to add specific functionality through scripts and programs written in Python by means of an interpreter and a series of specific libraries. PyQGIS is the library that allows Python to interact with the features of QGIS. PyQT allows the creation of customized graphical interfaces such as "widgets" (buttons, labels, tables, drop-down menus, etc.) for insertion and data editing; furthermore, through the QT Designer software there is the possibility of associating specific and complex graphic interface forms for data entry to each layer of the QGIS project.

The plugins published in the official repository of QGIS extensions are easy to install: it is sufficient to search using keywords in the manager integrated in the software menu (Figure 1); after installation, the toolbar containing the specific tools is automatically displayed. 


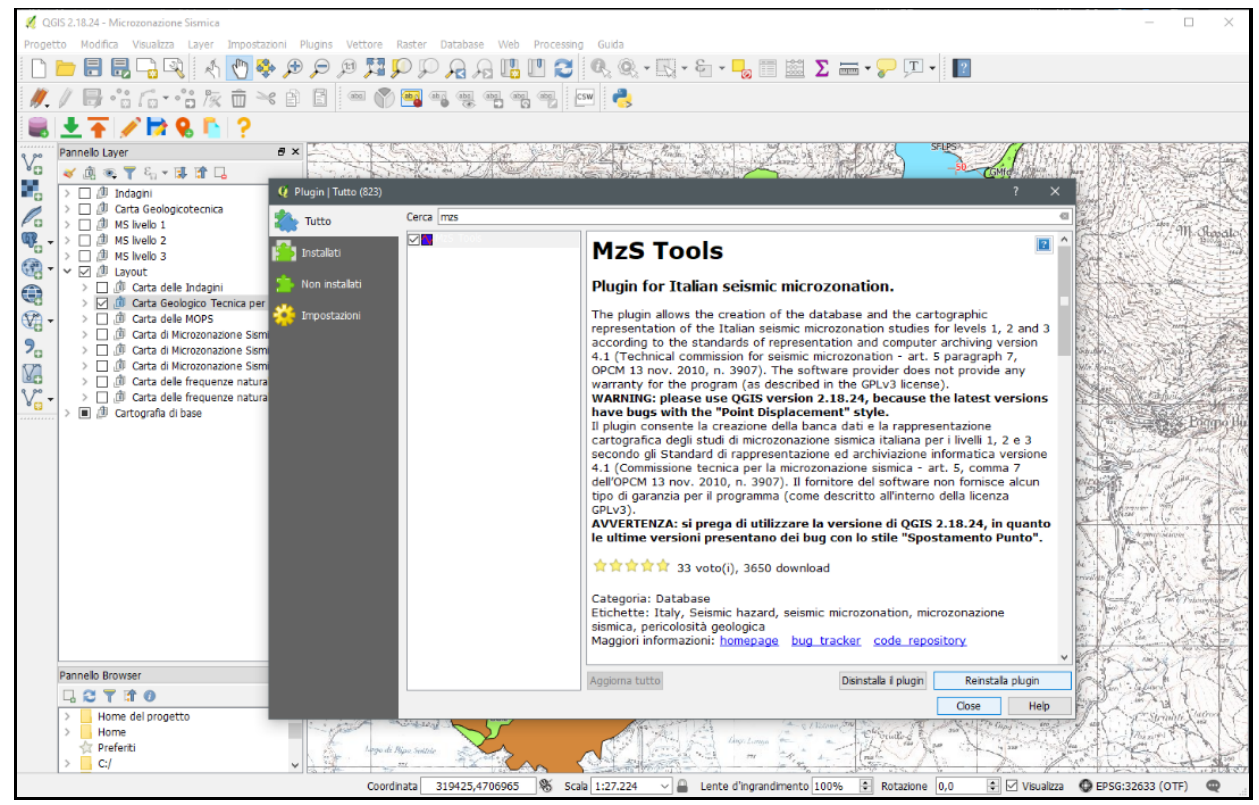

Figure 1. Installing the MzS Tools plugin from the QGIS plugin manager

MzS Tools meets to a series of practical needs of the geologist profession by simplifying some aspects of the management process of an SM study listed below:

- Automatic generation of the project structure;

- Geodatabase in SQLite / SpatiaLite format

- Topological editing of georeferenced geometries to ensure the correctness and coherence of the geographic layers;

- User-friendly data entry interfaces for the attribute tables of the vector layers and for the survey database, with systems to simplify the encoding of information such as the reference to the types of data, admissible values of the parameters, and relationships between the tables, etc.

- SM project import tools in shapefile format and Microsoft Access database;

- Symbol libraries in scalable vector file (SVG) format;

- QGIS project with visualization rules of the geographic layers aimed at the cartographic representation of the SM maps;

- Automated map layouts;

- SM project export tool in shapefile (geographic data) and SQLite (survey database) format.

\subsection{Database structure}

A fundamental element of MS is the definition of the subsoil model of the study area. To define the subsoil model it is necessary to have a dataset of georeferenced information such as a topographic base map (with a scale of at least 1: 10,000), geological, geologicaltechnical, hydrogeological and geomorphological maps.

Lithostratigraphic and geotechnical data are also required from geognostic surveys and geophysical data that define the velocity of propagation of seismic waves within the covering deposits and geological units of the substrate.

The information to be filled in the survey database is detailed in the SM Standards. The SM Standards database is a Microsoft Access Relational Database Management System (RDBMS).

The data entry is set up on a series of rules (types of data, encodings, relationships between the tables), to ensure the correctness and integrity of the information. The geographic layers described in the SM Standards have a single table of attributes, with the exception of surveys in which alphanumeric information is stored in a series of related tables in a Microsoft Access Database, linked to georeferenced geometric objects (shapefile or ESRI geodatabase) with a 1:1 relation. The geological and geophysics surveys are contained in two different geographic layers characterized by punctual ("Ind_pu") and linear 
("Ind_ln") geometries. One of the biggest drawbacks, when using these different formats is manually relate the geometries of the geological surveys to the related attributes contained in the Microsoft Access database.

MzS Tools has solved this problem by introducing the SQLite / SpatiaLite format with which it has been possible to integrate both geographic and alphanumeric information in a single geodatabase, moreover, new features have been introduced to automate many operations and ensure greater quality and control of data thanks to the potential of QGIS. SQLite is a full-featured Relational Database Management System (RDBMS) that uses a single file (with the ".sqlite" extension) for storing information on desktop platforms. SpatiaLite is an extension with spatial functionality in SQLite for the support and management of georeferenced data. It is an open, free, compact format based on OGC (Open Geospatial Consortium) standards. SQLite/SpatiaLite allows you to build single-user, lightweight and high-performance geodatabases and to interact through SQL (Structured Query Language) and a complete set of spatial functions. Figure 2 shows the scheme of the seismic microzonation database (SMDb).

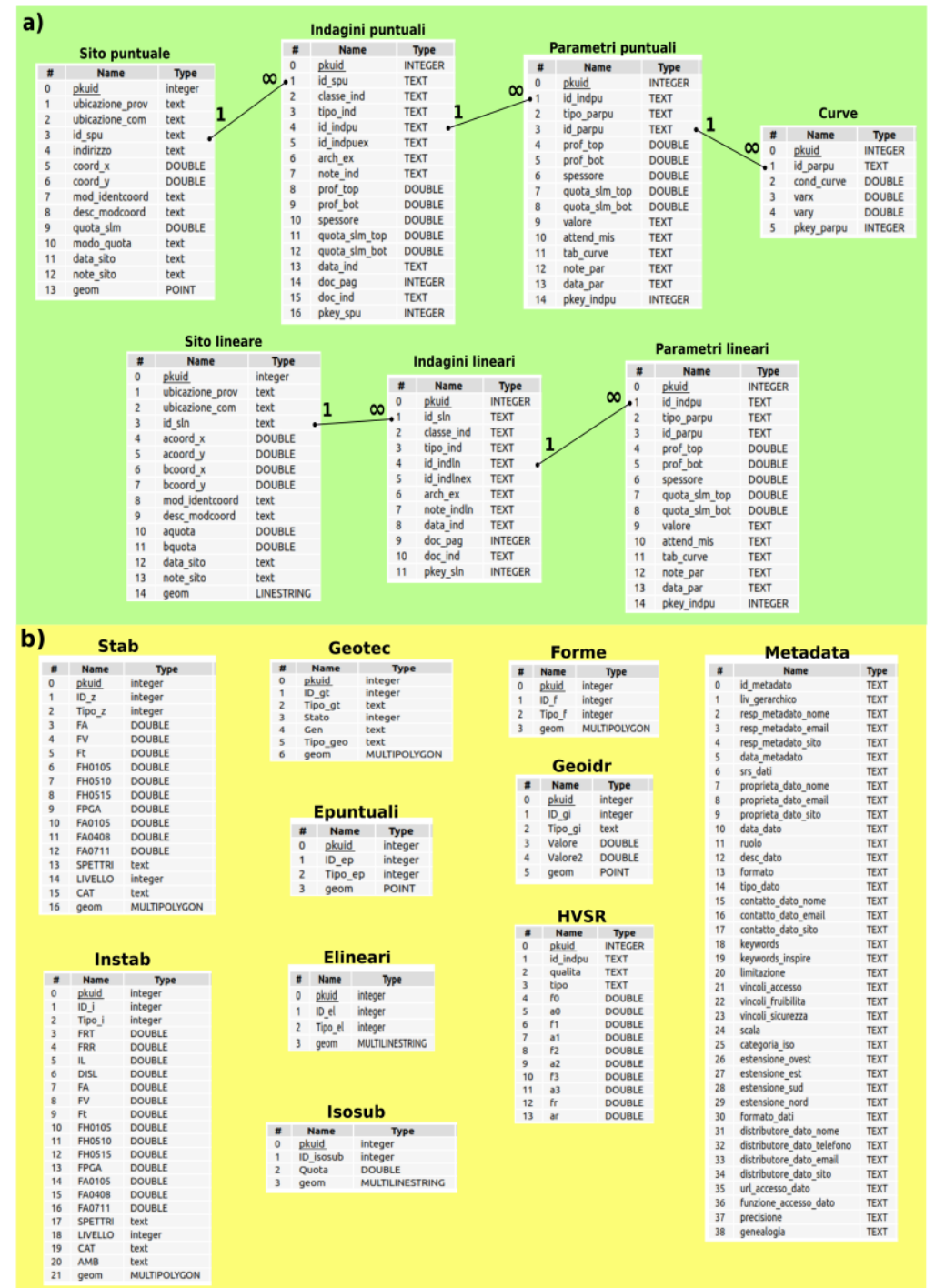

Figure 2. Structure of the database according to the SM Standards: a) database of punctual and linear surveys; b) geographic database of seismic microzonation (for the description refer to Table 1 and Appendix A).

The structure of the SMDb consists of 17 tables of which: 11 tables with geographic information and attributes relating to the objects; 5 tables with only the attributes connected to the geognostic surveys and one containing the metadata of the GIS project. To 
these are added the views (virtual tables based on specific queries to create filters on certain objects of the layers for the SM maps) and accessory tables (lookup tables) of the GIS project (Figure 3) to help manage the layouts and to facilitate the insertion of data into the forms through special drop-down menus containing the descriptions of the numeric codes.

\begin{tabular}{|c|c|}
\hline Views & Accessory tables \\
\hline 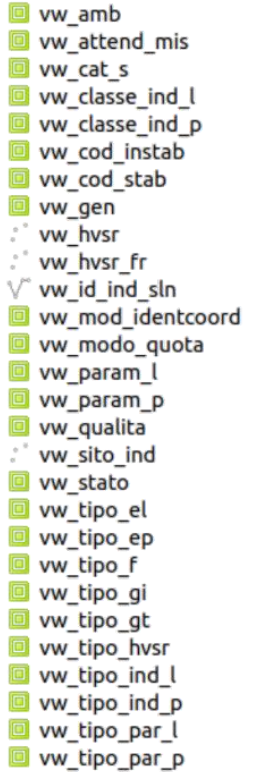 & 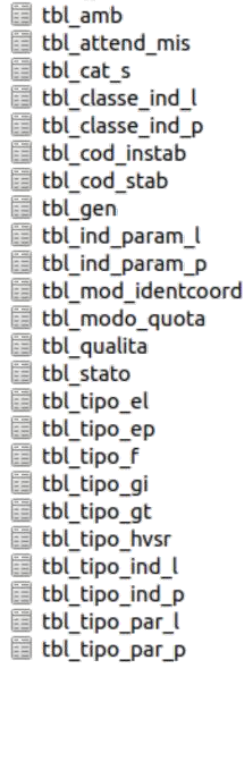 \\
\hline
\end{tabular}

Figure 3. Tables and views of the geodatabase managed by MzS Tools

The geodatabase managed by MzS Tools has been structured in order to store the information as shown in Table 1.

Table 1. The geodatabase layers and the maps according to the SM Standards.

\begin{tabular}{|c|c|}
\hline MAPS & Geographic datasets required \\
\hline $\begin{array}{l}\text { Map of geological surveys } \\
\text { (Carta delle Indagini) }\end{array}$ & $\begin{array}{l}\text { - Ind_pu: punctual geological and geophysics sur- } \\
\text { veys. } \\
\text { - Ind_ln: linear geological and geophysics surveys. } \\
\text { - CdI_Tabelle: structure of survey related tables (Fig- } \\
\text { ure 2a). }\end{array}$ \\
\hline $\begin{array}{l}\text { Geological Technical Map } \\
\text { (Carta geologico-tecnica) }\end{array}$ & $\begin{array}{l}\text { - Forme: surface or buried forms that have an areal } \\
\text { extension. } \\
\text { Elineari: structural, morphological and tectonic ele- } \\
\text { ments of linear geometry. } \\
\text { - Epuntuali: morphological elements of punctual ge- } \\
\text { ometry. } \\
\text { - Geoidr: geological and hydrogeological point ele- } \\
\text { ments. } \\
\text { Geotec: information on geological-technical units, } \\
\text { divided into cover soils and bedrocks. } \\
\text { Instab: areas of attention due to movements or land- } \\
\text { slides. }\end{array}$ \\
\hline $\begin{array}{l}\text { Map of Homogeneous Mi- } \\
\text { crozones in Seismic Perspec- } \\
\text { tive } \\
\text { (Carta delle microzone } \\
\text { omogenee in prospettiva sismica } \\
\text { - Carta delle MOPS) }\end{array}$ & $\begin{array}{l}\text { - Forme: surface or buried forms that have an areal } \\
\text { extension } \\
\text { Elineari: structural morphological and tectonic ele- } \\
\text { ments (active and capable faults) of linear geome- } \\
\text { try }\end{array}$ \\
\hline
\end{tabular}


- Epuntuali: morphological elements of punctual geometry

- Ind_pu: HVSR surveys (environmental noise measurements)

- Stab: stable areas and stable areas susceptible to local amplification

- Instab: areas of attention for instability (slope, liquefaction, active and capable faults, differential subsidence-collapses of cavities-sinkholes, overlapping of different instabilities)

- Stab: stable zones and stable zones susceptible to lo-

Seismic Microzonation Map

(Carta di microzonazione

sismica) cal amplification with amplification factor ( $\mathrm{Fa}$ ).

- Instab: areas of attention for instability with amplification factor $(\mathrm{Fa})$ and specific instability parameters.

Seismic microzonation Map (Level 2 and / or 3) considered in the periods (S): $0.1 \leq \mathrm{S}<0.5 ; 0.4 \leq \mathrm{S}<0.8$ and $0.7 \leq$ $\mathrm{S}<1.1$

There are also other elements in the database, such as functions and triggers, necessary for the automation of some procedures and to ensure the maintenance of data integrity.

\subsection{The QGIS project structure}

The MzS Tools "New project" tool allows you to generate an archive structure and a QGIS project for a new MS study. Once the Municipality has been chosen, the plugin automatically performs a series of settings on the project: the database is in fact prepared, through special views ("virtual" tables based on SQL queries), the base map and the layouts are edited and centered on the borders of the Municipality (boundaries of administrative units for statistical purposes ${ }^{2}$ ) and set to an appropriate zoom level that includes the entire administrative area, furthermore the form requires the insertion of some metadata such as the author's information, data ownership and the nominal reference scale etc.

The QGIS project presents a tree structure represented in the "Layers Panel" (Figure 4). The Layout group, in particular, contains layers specifically set for cartographic output, while the other layer groups are dedicated to editing and entering data.

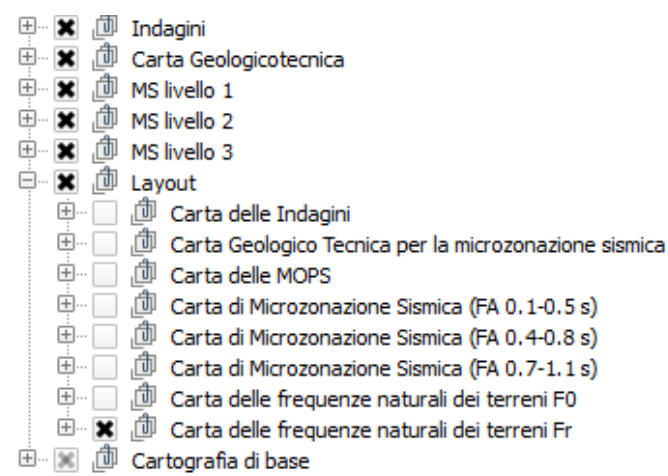

Figure 4. The main layer groups within the project's table of contents (TOC).

2 https://www.istat.it/it/archivio/222527 
Some utility layers such as municipal limits ${ }^{3}$ and some WMS services ${ }^{4}$ are preloaded in the "Cartografia di base" group, but others can be added according to project needs. All the layers present within these groups have specific styles created through logical expressions that replicate the indications of the SM Standards (Figure 5).

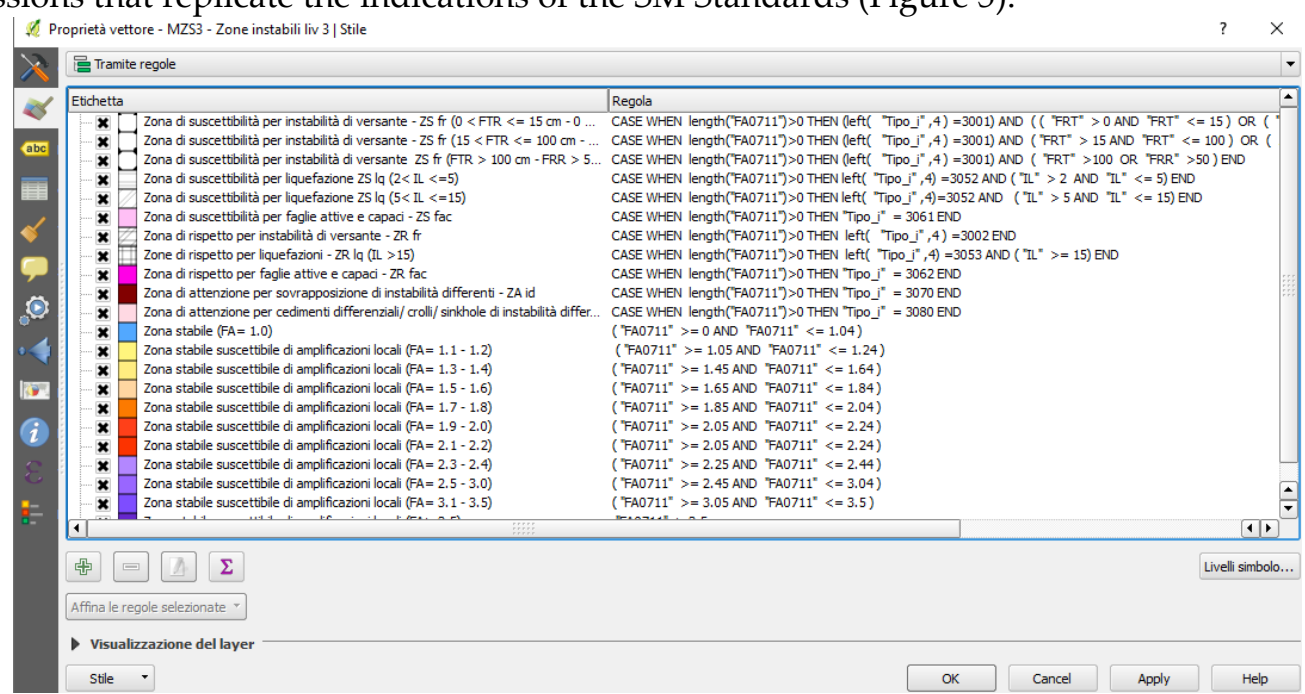

Figure 5. Style rules applied to the layers of the QGIS project.

The project also contains the one to many (1-N) relationships and joins existing between the geological survey tables and the related geographic objects (Figure 6)

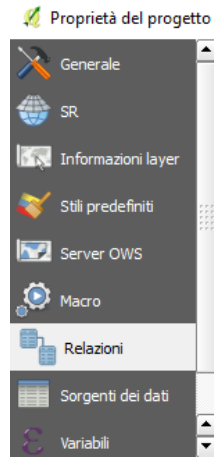

\begin{tabular}{|c|c|c|c|c|c|c|c|}
\hline & Nome & Layer figlio & :ampo di riferimentc & Layer padre & ગo a cui si fa riferim & Id & \\
\hline 1 & fk___indagini_par.... & Parametri lineari & id_indln & Indagini lineari & id_indln & fk___indagini_parametri & \\
\hline 2 & fi___sit__indagini & Indagini lineari & id_sin & Siti lineari & id_sin & fi___sit__indagini & \\
\hline 3 & fk____indagini_hvsr & $\begin{array}{l}\text { Indagine stazione } \\
\text { singola (HVSR) }\end{array}$ & id_indpu & Indagini puntuali & id_indpu & fk____indagini_hvsr & \\
\hline 4 & fi____indagini_pa.... & Parametri puntuali & id_indpu & Indagini puntuali & id_indpu & fk__p_indagini_parametri & \\
\hline 5 & fk____parametri_... & $\begin{array}{l}\text { Curve di } \\
\text { riferimento }\end{array}$ & id_parpu & Parametri puntuali & id_parpu & fk_p_parametri_curve & \\
\hline \multirow[t]{3}{*}{6} & fik____iti__indagini & Indagini puntuali & id_spu & Siti puntuali & id_spu & fk____sit__indagini & \\
\hline & & & th Aggiung & gi relazione $\square R$ & imuovi relazione & & \\
\hline & & & & & OK & Cancel & Help \\
\hline
\end{tabular}

Figure 6. Style rules applied to the layers of the QGIS project.

\subsection{Data entry and geografical editing}

To facilitate the storage of alphanumeric data in the SMDb, 23 data acquisition forms have been configured within the QGIS project, corresponding to the input elements of the SM Standards. In general, after editing a geometry, the corresponding interface for inserting attributes is displayed.

The data acquisition form can be more or less articulated according to the amount of information related to the inserted geometry. Table 2 lists and describes of the forms divided by theme:

Table 2. Data entry Forms for the data entry of the SM geodatabase divided by cartographic theme

\begin{tabular}{cc}
\hline Map & Data entry Form \\
\hline $\begin{array}{c}\text { Geological surveys Map ( Carta delle } \\
\text { Indagini) }\end{array}$ & Sito puntuale (punctual site) \\
& Indagini puntuali (punctual surveys) \\
Parametri puntuali (punctual parameters)
\end{tabular}

\footnotetext{
${ }^{3}$ https://www.istat.it/it/archivio/222527

${ }^{4}$ WMS services are: Topographic Map of Italy" at scale 1:25.000 of Italian Military Geographic Institute (IGM) http://wms.pcn.minambiente.it/ogc?map=/ms_ogc/WMS_v1.3/raster/IGM_25000.map; Digital terrain model - 20 meters, http://wms.pcn.minambiente.it/ogc?map=/ms_ogc/WMS_v1.3/raster/DTM_20M.map.
} 
Curve di riferimento (reference diagram) Indagini a stazione singola - HVSR (HVSR surveys)

Sito lineari (linear site)

Indagini lineari (linear surveys)

Parametri lineari (linear parameters)

Elementi geologici e idrogeologici puntuali (

Geological and hydrogeological elements)

Geological-technical Map (Carta geologico tecnica per la microzonazione sismica)

Elementi puntuali (punctual elements)

Elementi lineari (linear elements)

Instabilità di versante (slope instability)

Forme (geomorphologic landforms)

Unità geologico-tecniche (Geological-technical Units)

\begin{tabular}{cc}
\hline $\begin{array}{c}\text { SM level 1 Map (Carta delle microzone } \\
\text { omogenee in prospettiva sismica } \\
\text { MOPS) }\end{array}$ & $\begin{array}{c}\text { Isobate liv 1 (Isobaths of level 1) } \\
\text { Zone instabili liv1 (Unstable zones of level 1) } \\
\text { Zone stabili liv1 (Stable zones of level 1) }\end{array}$ \\
\hline SM level 2 Map (Carta di & Isobate liv 2 (Isobaths of level 2) \\
microzonazione sismica di livello 2) & $\begin{array}{c}\text { Zone instabili liv. 2 (Unstable zones of level 2) } \\
\text { Zone stabili liv. 2 (Stable zones of level 2) }\end{array}$ \\
\hline SM level 3 Map (Carta di & Isobate liv. 3 (Isobaths of level 3) \\
microzonazione sismica di livello 3) & $\begin{array}{c}\text { Zone Instabili liv. 3 (Unstable zones of level 3) } \\
\text { Zone stabili liv.3 (Stable zones of level 3) }\end{array}$ \\
\hline
\end{tabular}

Figure 7 illustrates the forms for the data entry of punctual geological surveys. All the forms of MzS Tools are described in detail in Appendix A, where the complexity of the data entry is highlighted through the modules that are managed optimally thanks to the potential of the QGIS project.

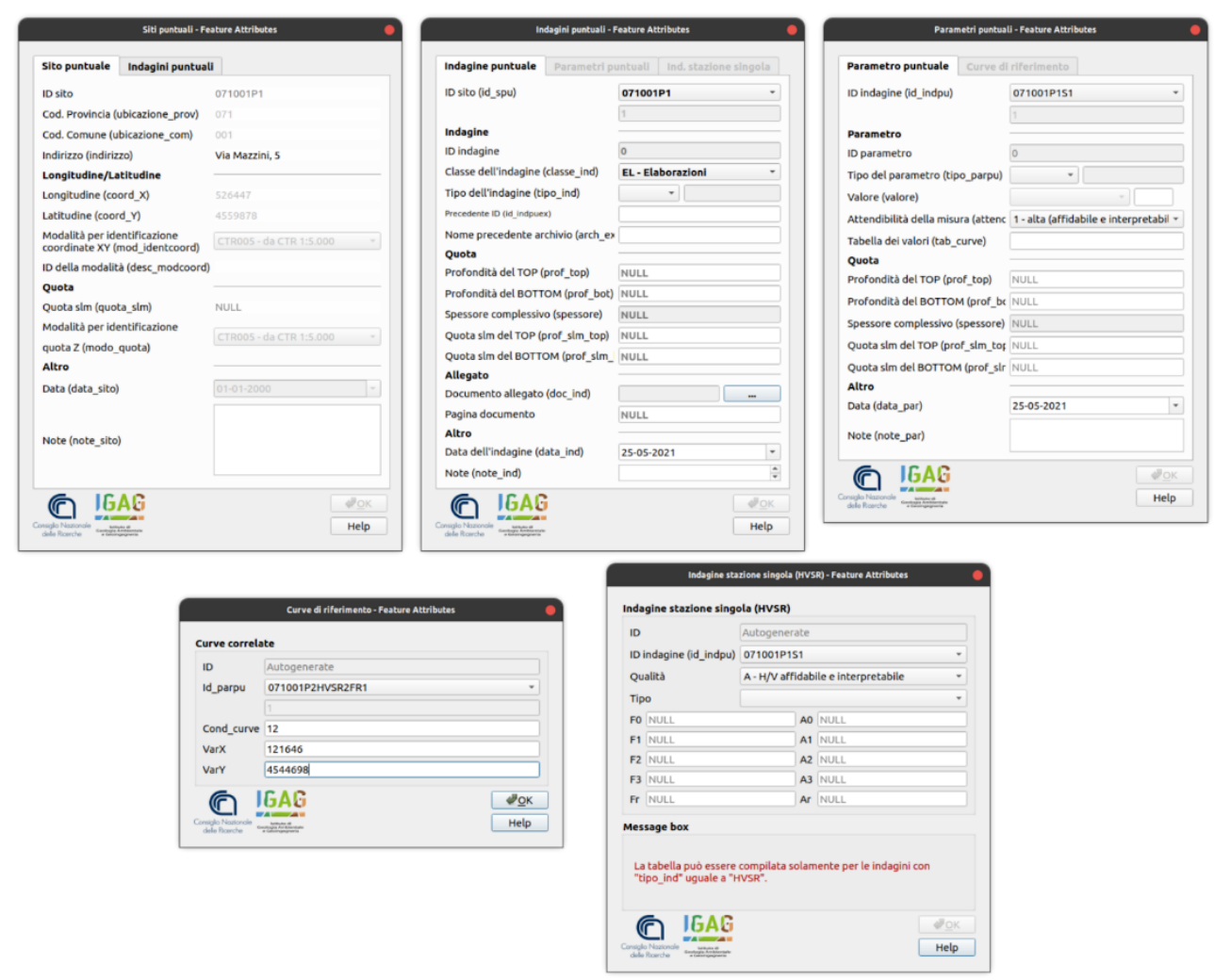

Figure 7. Data entry Forms for the attributes of punctual geological surveys: Siti puntuali, Indagini puntuali, Parametri puntuali, Curve di riferimento e Indagine a Stazione singola (HVSR). 


\section{Topological editing}

SM studies must respect some topological relationships existing between layers, as in the case of layers concerning stable and unstable zones, and geological-technical units (Figure 8).

The MzS Tools plugin works with the topological editing features introduced in the QGIS project through control rules on the geometry of the layers. In particular, the topological controls concern the intersections between polygons of the same layer (stable, unstable zones and geological-technical units) and the possible intersections between polygons of different layers (stable and unstable zones, for each level of SM study).

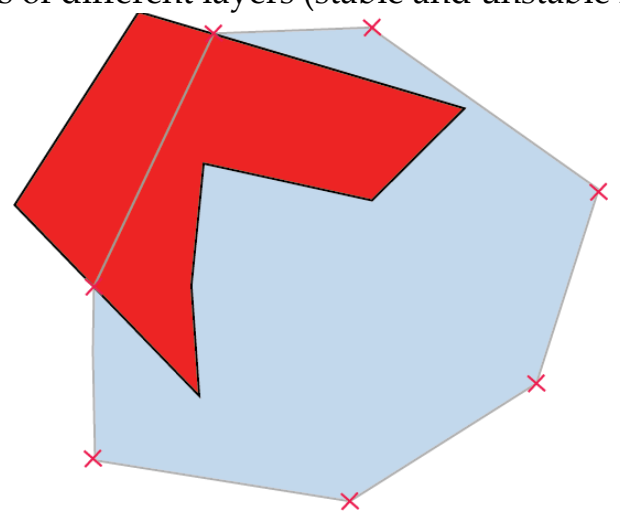

Figure 8. Example of overlap between polygons

\section{Import tool}

MzS Tools plugin provides the "Import project folder to geodatabase" tool (Figure 9) for importing data from an existing project, compliant with SM Standards. The plugin tool is able to automatically transfer the data coming from the shapefiles and the Microsoft Access database "CdI_tabelle" and all the files present in the folders of the "old" project to the new storage structure. To import table data from the Microsoft Access database it is necessary to convert to textual format (these operations are described in detail in the plugin manual).

After importing the data, a textual report is written which lists the operations performed and the possible errors found.

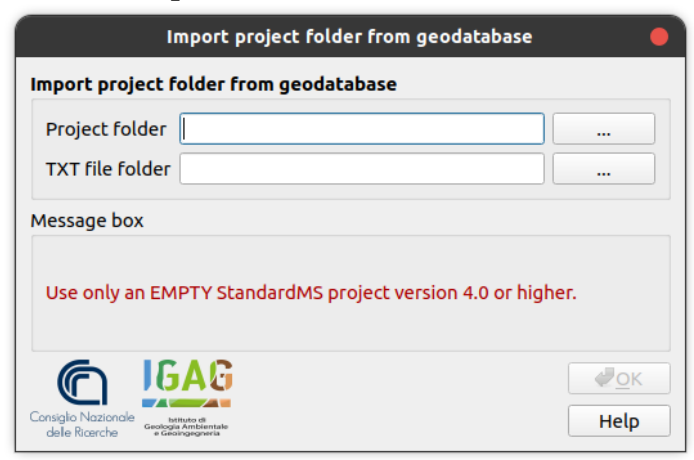

Figure 9. Form for importing a seismic microzonation project into the MzS Tools plugin

\section{Export tool}

The storage structure of the plugin does not correspond to that provided by the SM Standards, as it is optimized for use with QGIS. The transformation into the structure according to the MS Standards can be performed automatically using an "Export" tool (Figure 10) which works as follows: 


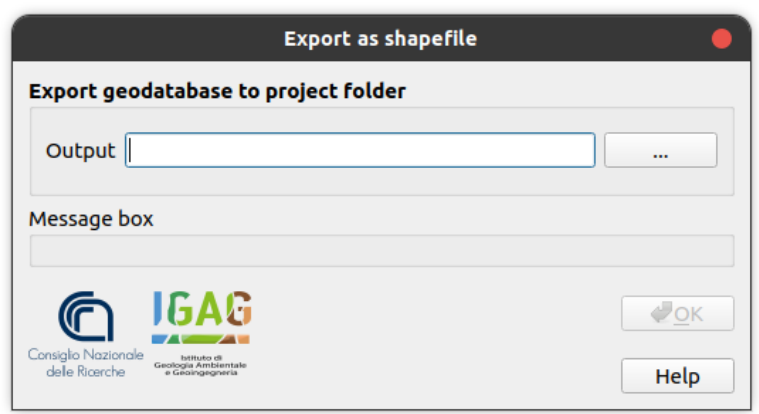

Figure 10. Form for exporting the seismic microzonation project in the SM Standards archiving format

The tool requires the folder in which to export the project, at the end it generates a textual report with the result of the project export operations.

\section{Layout Maps}

The layouts are automatically set to the geographical position of the Municipality selected in the initial phase of the project. Figure 11 shows the eight established maps. T

he Layout function in QGIS is accessible from the main menu in the Project section. Below is the list of maps present in MzS Tools:

- Geological Survey Map.

- Geological-technical Map.

- Map of Homogeneous Microzones in a seismic perspective.

- Seismic microzonation Map (Level 2 and / or 3) considered in the periods (S):

○ $0.1 \leq \mathrm{S}<0.5$ Seismic microzonation Map;

○ $0.4 \leq \mathrm{S}<0.8$ Seismic microzonation Map;

○ $\quad 0.7 \leq \mathrm{S}<1.1$ Seismic microzonation Map;

- Map of the Natural Frequencies of the Soils:

○ (F0), to represent the peak F0 values;

○ (Fr), to represent the most representative frequency value.

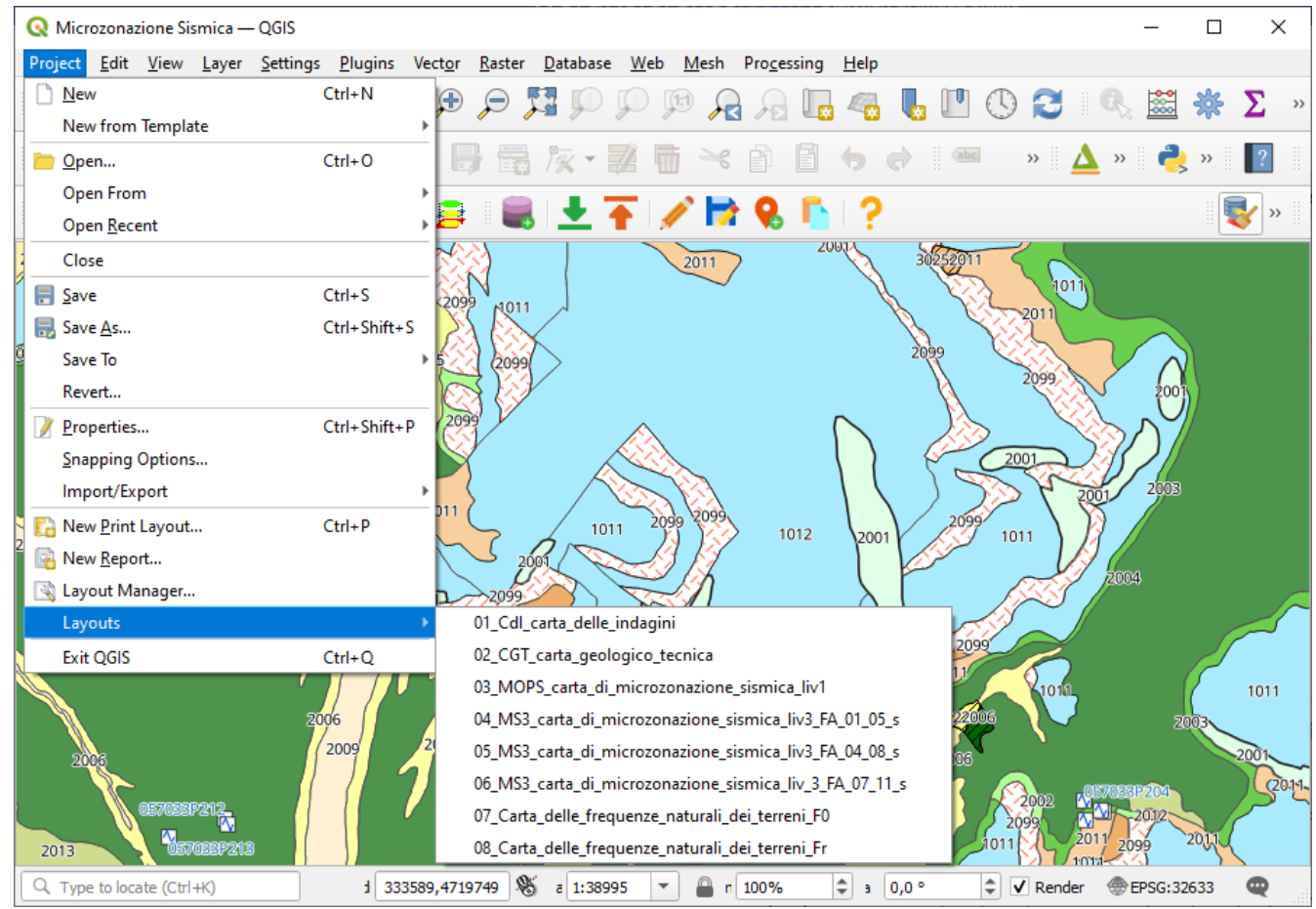

Figure 11. Layout of SM Maps present in the QGIS project of the MzS Tools 
To act on the "layouts", it is necessary to activate certain layers of the QGIS project, set for the cartography located in the group layer "Layout" (Figure 12)

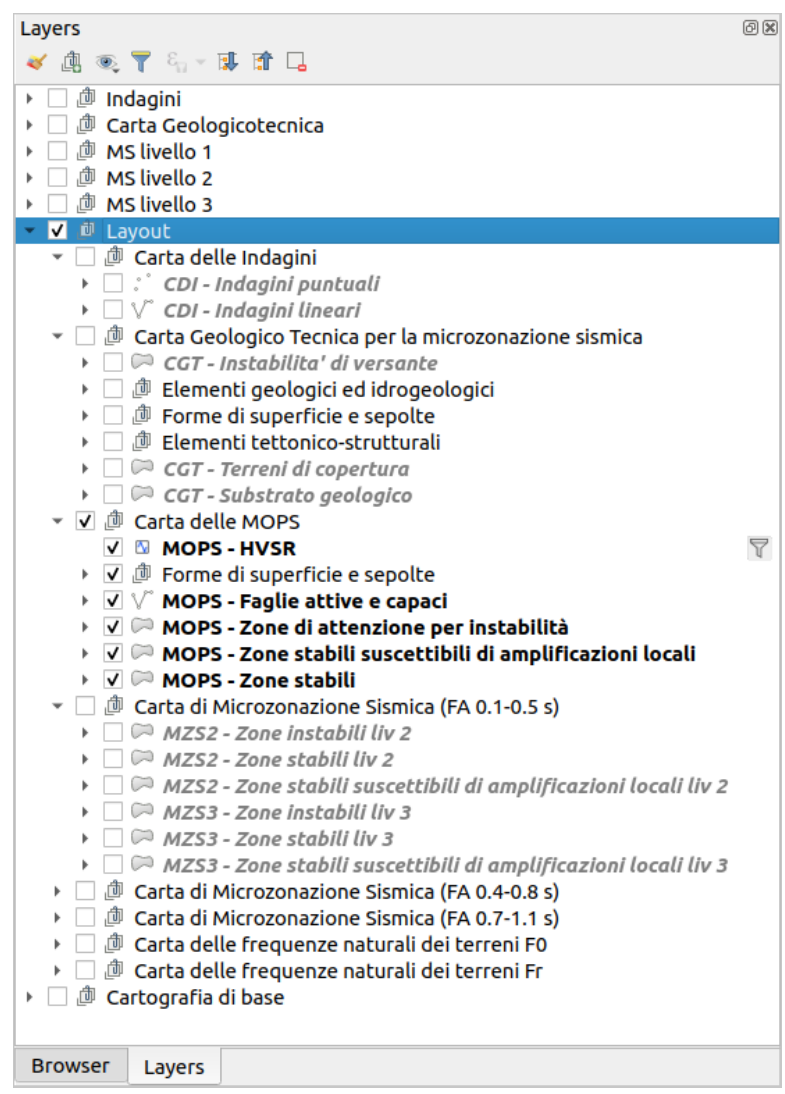

Figure 12. QGIS project layers set for SM cartography

In this way, the layers are organized and displayed within the layouts according to the criteria of thematic cartography; for example, for punctual geological surveys, a visualization according to the QGIS "point displacement" style is used, which allows to distinguish the different surveys associated with each site (Figure 13).

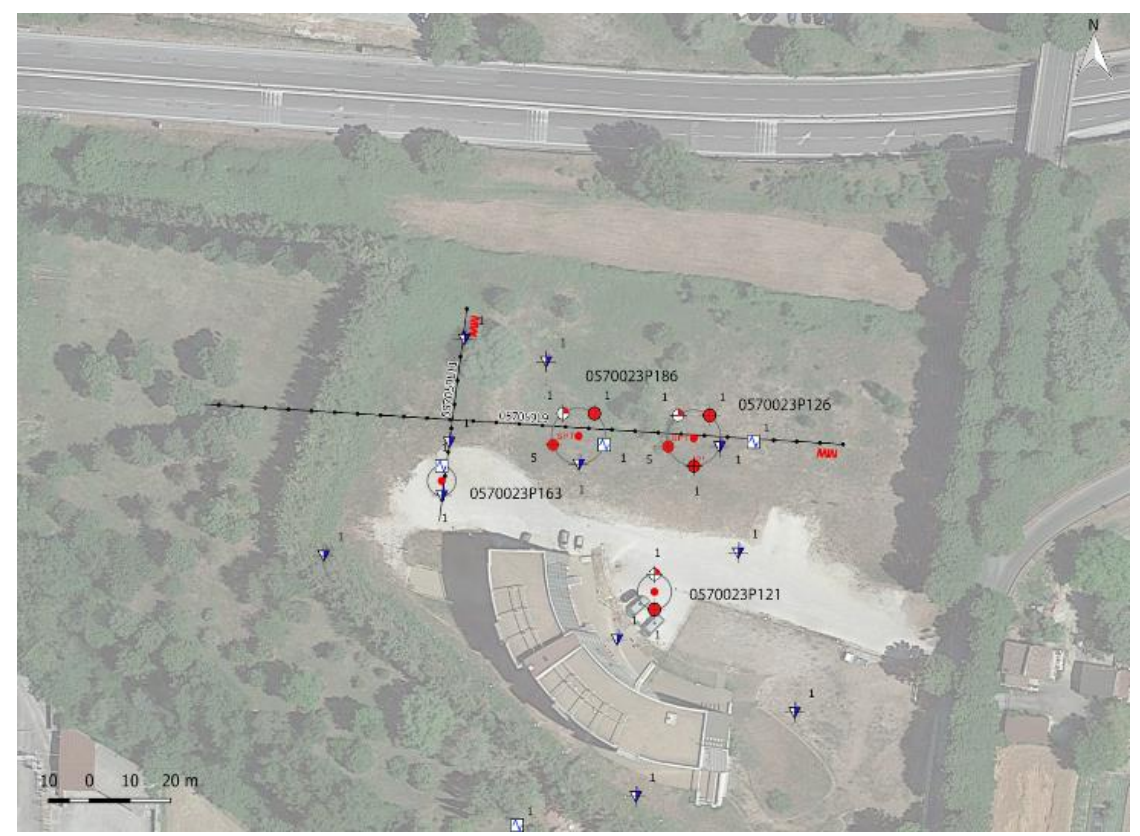

Figure 13. Punctual geological surveys relating to a punctual survey site 
Figures 14 represent the examples of the cartographic layouts managed and created with the QGIS project by MzS Tools.

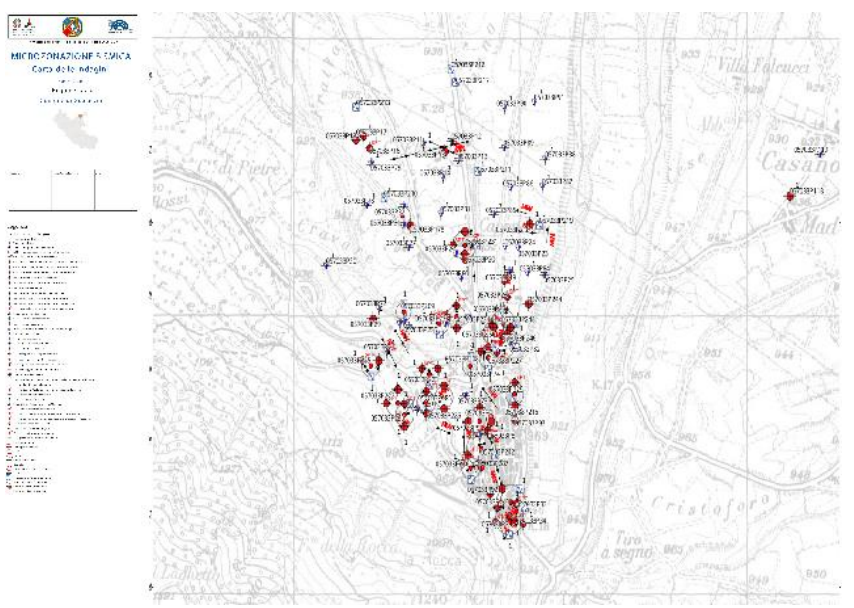

(a)

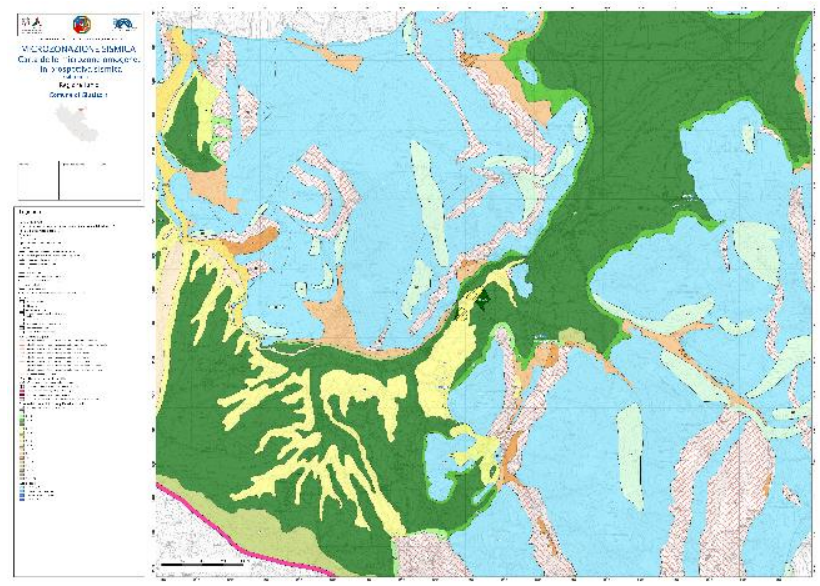

(c)

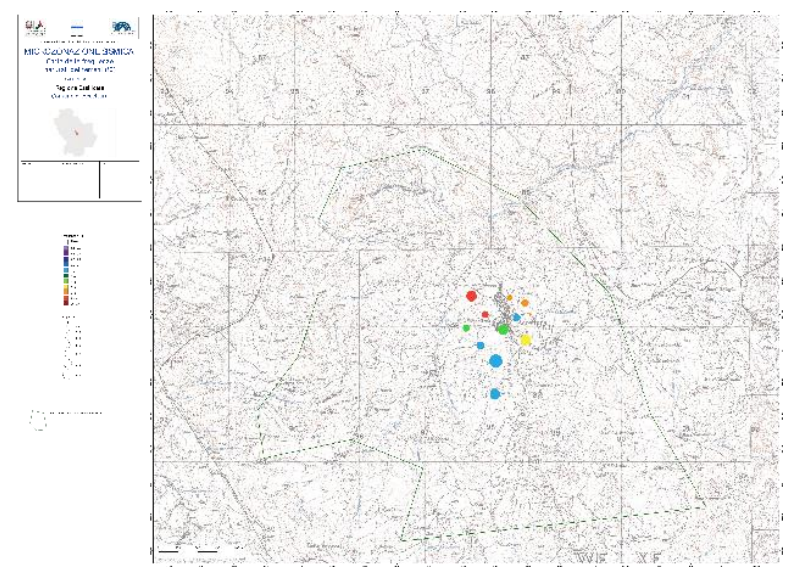

(e)

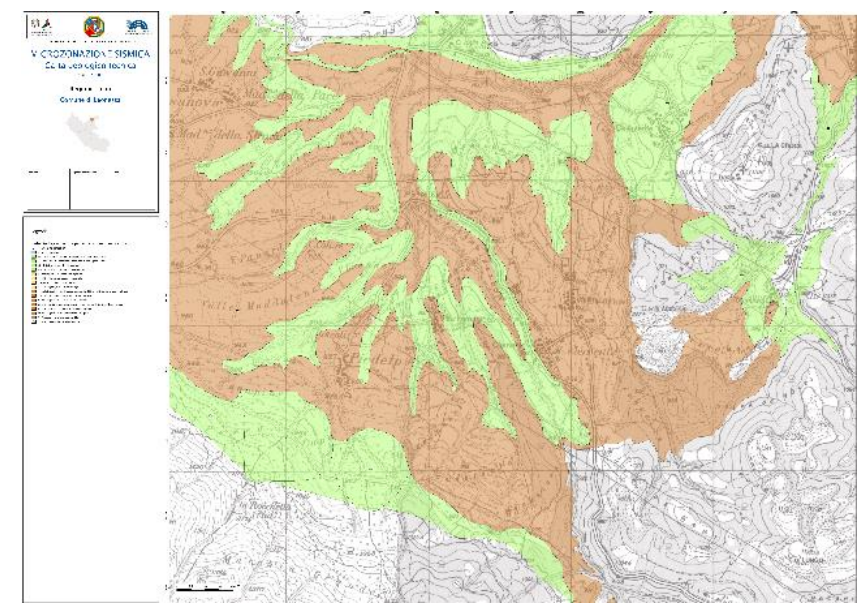

(b)

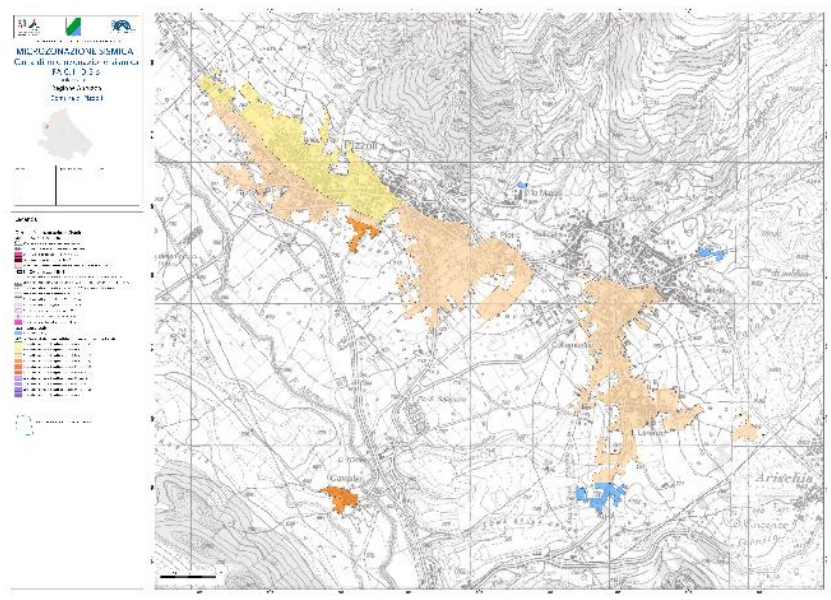

(d)

Figure 14. Examples of Cartographic layouts managed and created with the QGIS project by MzS Tools. (a) Layout of the Geological Survey Map (CdI - Carta delle indagini); (b) Layout of Geological-technical Map (CGT - Carta geologico tecnica); (c) Layout of Map of Homogeneous Microzones in a seismic perspective (MOPS - Carta di microzonazione sismica liv.1); (d) Layout of Seismic microzonation Map (MS3 - Carta di microzonazione sismica); (e) Layout of Map of the Natural Frequencies of the Soils. 


\section{Discussion and comparison with other approaches}

The implementation of MS studies requires the use of software tools that allow you to perform different types of operations on the data and to simplify repetitive tasks such as: data management within database structures and geodatabases; advanced editing; the design of GIS projects with different layers; the use of processing and display tools; the preparation of layouts for the production of maps; importing data and exporting to other formats; checking for topological errors and data coherence; etc.

The fundamental requirement, in Italy, regardless of the software and tools used, is compliance with the SM Standards (database and Maps). This requirement is essential for the approval of the SM studies by the Italian Civil Protection Department, which supervises the MS Project at the national level.

An SM study can currently be implemented with the following software tools:

- SoftMS 5 that allows the management of the information database of the alphanumeric attributes of the punctual and linear surveys;

- GIS software for editing georeferenced data and viewing map layers (for example ESRI ArcGIS or QGIS);

- Graphics Software for managing map layouts and for cartographic production (GIS software or graphics programs such as Adobe Illustrator; CorelDraw, Inkscape).

The use of generic software and tools not specifically aimed at MS studies can lead to a greater waste of time and a greater possibility of making mistakes, compared to using a specific tool.

In the context of MS the MzS Tools represents a comprehensive tool that assembles a number of useful tools, in a single environment based on the QGIS software, with the aim of simplifying the management of the database and GIS projects and creating maps in conformity with SM Standards. Geologists in the seismic microzonation studies of the Italian territory use MzS Tools. The plugin allows users to manage SM data and automate various types of tasks (project generation, data import and export, topological editing, integrity and validity checks on entered data). The QGIS project also includes ready to use layer styles and symbol libraries.

The main advantages in using this tool, compared to other tools and software, can be identified in time savings, due to the automation of different processes, and the production of SM studies compliant to the Standards and less prone to errors.

An example of the use of the software was the study conducted in the Municipalities of Casamicciola Terme, Forio, Lacco Ameno on the Island of Ischia affected by the seismic events of 21 August 2017, as well as the municipalities affected by the events of 2016 and 2017 in Central Italy.

Table 17 shows a comparison between the MzS Tools proposed solutions to ease some of the SM study challenges, and some of the possible alternative approaches. On the basis of these considerations it is possible to argue that using a specialized tool such as MzS Tools can be useful to reduce errors and study execution times, while ensuring Standards compliant results.

Table 3. Main features of the MzS Tools plugin and comparison with alternative approaches

\begin{tabular}{ccc}
\hline SM study feature & MzS Tools solution & Alternative approaches \\
\hline Project workspace & $\begin{array}{c}\text { Automatic generation of an opti- } \\
\text { mized archiving structure for a spe- }\end{array}$ & $\begin{array}{c}\text { Manually structure the workspace or } \\
\text { use the available generic templates. }\end{array}$ \\
\hline
\end{tabular}

\footnotetext{
${ }^{5}$ Available in the download section of the site of the Centro per la Microzonazione sismica e le sue applicazioni (www.centromicrozonazionesismica.it) in addition, two archiving structure models are currently available based on the use of shapefiles or file geodatabases (https://www.centromicrozonazionesismica.it/it/download/category/38-standardms-42).
} 
cific municipality. Standards com-

pliant structure generated by an export tool.

GIS project project including all of the required layers, styles, symbol libraries and layouts.
Manually build the GIS project (e.g. in ESRI ArcGIS), with required styles, symbols and cartographic layouts, by following the SM Standards specifications.
Data management

Data integrity and validity maintenance
Single Spatialite geodatabase containing both the georeferenced geometries and the alphanumeric tables for punctual and linear surveys.
Shapefile or file geodatabase related to a Microsoft Access database (as required by the SM Standards)

\begin{tabular}{|c|c|c|}
\hline $\begin{array}{l}\text { Data integrity and validity } \\
\text { maintenance }\end{array}$ & $\begin{array}{l}\text { Geodatabase integrated features } \\
\text { such as referential integrity checks, } \\
\text { functions and triggers to automate } \\
\text { code composition, lookup tables to } \\
\text { manage data domains. }\end{array}$ & $\begin{array}{l}\text { SoftMS or Microsoft Access } \\
\text { for the management of alphanumeric } \\
\text { survey data, and simple shapefiles for } \\
\text { georeferenced data }\end{array}$ \\
\hline Data entry & $\begin{array}{l}\text { QGIS user-friendly forms directly } \\
\text { integrated in the SM project, for all } \\
\text { the required layers. }\end{array}$ & $\begin{array}{l}\text { SoftMS or Microsoft Access, } \\
\text { only for alphanumeric survey data. }\end{array}$ \\
\hline $\begin{array}{l}\text { Editing of georeferenced } \\
\text { geometries }\end{array}$ & $\begin{array}{l}\text { Leverage the QGIS integrated topo- } \\
\text { logical editing, when required, to } \\
\text { avoid common errors, such as adja- } \\
\text { cent polygon overlaps. }\end{array}$ & $\begin{array}{l}\text { Manual configuration of any tools } \\
\text { made available by the software used } \\
\text { (e.g. topological features in ESRI } \\
\text { ArcGIS geodatabase formats). }\end{array}$ \\
\hline $\begin{array}{l}\text { Import of already } \\
\text { existing data }\end{array}$ & $\begin{array}{l}\text { Tool to automatically import data } \\
\text { from a SM Standards compliant ex- } \\
\text { isting project. }\end{array}$ & $\begin{array}{l}\text { Import data for every table, manually } \\
\text { regenerating ids and codes while } \\
\text { checking data integrity }\end{array}$ \\
\hline Map layouts & $\begin{array}{l}\text { Automatically generated layouts for } \\
\text { every required cartographic output, } \\
\text { customized for the selected munici- } \\
\text { pality. The QGIS project features ap- } \\
\text { propriately filtered and styled layers } \\
\text { for print layouts. }\end{array}$ & $\begin{array}{c}\text { Manual construction of the layouts } \\
\text { from the ground up in a GIS or } \\
\text { graphics software. }\end{array}$ \\
\hline
\end{tabular}


Possible and further developments of the plugin could concern the design of some tools for data analysis such as:

- extract geological and geotechnical lithostratigraphy data from geological surveys to parameterize geological units and stable zones;

- identify areas with a slope greater than $15^{\circ}$, this value is a limit beyond which the seismic signal is amplified;

- define the automatic extension of the zones of attention, susceptibility and respect for active and capable faults (FAC) by geoprocessing calibrated on the type of faults (normal, inverse, transcurrent) and on the geometric ratio FW/HW (footwall / hang wall).

This would allow defining some geometric limits of the microzones allowing to improve the MS studies and to refine the parameterization and consequently a better cartographic representation.

\section{Conclusions}

The realization of MzS Tools in the field of seismic microzonation studies has allowed performing in optimally different types of operations that constitute the strengths of this project, which can be defined below:

- Creating, managing and editing data within database structures and geodatabases has made it possible to create a single and complete database in the SQLite / SpatiaLite format.

- Management through the ad hoc QGIS project of the different layers, both basic and thematic. The project allowed the creation of ad hoc views for editing and cartographic representation.

- Input and encoding of structured data through forms has allowed the elimination of transcription/digitization errors and the data entry of attributes in tables related to each other in a complex way.

- Importing data from previous projects allows you to update SM studies quickly by leveraging the performance of the plugin such as the integrity check of codes and geometries

- Export to other formats allows for interoperability with other software and simple data sharing.

- Topological editing of the layers with rules of the SM Standards, this process allows the elimination of geometric errors as well as a correct digitization of the objects in relation to the themes to be represented in the maps.

- Automatic setting of map layouts with legend, symbolism, geographical overview of the Region and logos based on the selection of the Municipality under study.

MzS Tools responds to a series of practical needs, giving the authors of seismic microzonation studies the possibility to use a single software environment and to simplify many aspects of the process of managing a project and producing the final cartographic outputs, through a series of tools that integrate and extend the basic ones present within QGIS.

MzS Tools is published through the official QGIS plugin repository and can be downloaded directly through the QGIS extension management interface. Software development is still in progress for the introduction of new functions and for the improvement of existing ones. Being an open source product, the development of the Plugin is open to anyone who wants to contribute, such as programming code, suggestions and indications, through the GitHub platform at https://github.com/CNR-IGAG/mzs-tools.

MzS Tools was created to facilitate seismic microzonation studies but the methodology developed for its implementation can be easily exported with appropriate modifications and adapted in other contexts where it is required: a relational data organization; a complex GIS project with data entry forms and topological editing rules; a cartographic output complete with automatic symbology and layout; all this is possible thanks also to the characteristics of the QGIS software which provides flexible and reliable tools thanks 
to the commitment of a community of developers and researchers attentive to the needs of modern research and free and open source technology.

Supplementary Materials: The following are available online at www.mdpi.com/xxx/s1, Video: S1 new project; S2 basemap: S3 Layers; S4 inserimento_sito_indagine; S5 inserimento_indagini; S6 inserimento_parametri_indagini:S7 inserimento_curve_indagini_puntuali; S8 topological_editing; S9 editing_stable_unstable_zones; S10 symbology_and_layers; S11 layout_maps; S12 import_SM_project; S13 export_project; S14 copy_stab_unstab_layers; S15 add_sito_puntuale_using_XY_wgs84utm33n_coordinate; S16 HVSR.

Author Contributions: "Conceptualization, Giuseppe Cosentino and Emanuele Tarquini; methodology, Giuseppe Cosentino and Emanuele Tarquini; software, Emanuele Tarquini and Francesco Pennica; writing-original draft preparation, Giuseppe Cosentino; writing - review and editing, Giuseppe Cosentino, Francesco Pennica, Francesco Stigliano and Giuseppe Cavuoto; visualization, Giuseppe Cosentino; supervision, Giuseppe Cavuoto; funding acquisition, Francesco Stigliano. All authors have read and agreed to the published version of the manuscript.

Funding: This research received no external funding.

Acknowledgments: Thanks to Monia Coltella, precious mentor of SM Standards and Gian Paolo Cavinato for the moral and intellectual support.

Conflicts of Interest: The authors declare no conflict of interest

\section{Appendix A}

This Appendix A describes the functions of the 23 forms of the QGIS project for data entry of the SM database. The exact data entry is very important for the drawing up of the maps as the values of the attribute codes are linked to the symbology of the cartographic project. Further information on the subject is contained in the on line user manual (https://mzs-tools.readthedocs.io/it/latest/).

\section{References}

1. Antoniou A. A., Papadimitriou A. G, Tsiambaos G. A geographical information system managing geotechnical data for Athens (Greece) and its use for automated seismic microzonation. Nat Hazards 2008, 47, 369-395.

2. Bhatt N., Pancholi V, Chopra S., Rout M. M, Shah R. D., Kothyari G. Rapid seismic hazard assessment of the Sabarmati River basin in Gujarat State, Western India using GIS techniques. Bulletin of Engineering Geology and the Environment, 2019, 78, 3927-3942.

3. Dhar S., Rai A. K., Nayak P. Estimation of seismic hazard in Odisha by remote sensing and GIS techniques. Nat Hazards, 2017, 86, 695-709

4. Ganapathy G. P. First level seismic microzonation map of Chennai city - a GIS approach. Nat. Hazards Earth Syst. Sci., 2011, 11, 549-559.

5. Kienzle A., Hannich D., Wirth W., Ehret D., Rohn J., Ciugudean V., Czurda K. A GIS-based study of earthquake hazard as a tool for the microzonation of Bucharest. Engineering Geology 2006, 87, 13-32.

6. Kim H. S., Chung C. K. Integrated system for site-specific earthquake hazard assessment with geotechnical spatial grid information based on GIS. Nat. Hazards 2016, 82, 981-1007

7. Mahajan A. K., Slob S., Ranjan R., Sporry R., Champati ray P. K, van Westen C. J. Seismic microzonation of Dehradun City using geophysical and geotechnical characteristics in the upper $30 \mathrm{~m}$ of soil column. J Seismol. 2007, 11, 355-370

8. Mohanty W. K. and Walling M. Y. First Order Seismic Microzonation of Haldia, Bengal Basin (India) Using a GIS Platform. Pure appl. geophysics. 2008, 165, 1325-1350

9. Moscatelli M., Pagliaroli A., Mancini M., Stigliano F., Marini M., Simionato M., Cavinato GP \& Colombi A. Seismic microzonation of level 1 of the Historic Center of Rome. Rendiconti Online Società Geologica Italiana 2015, 33, 63-70

10. Moustafa S. S. R, Al-Arifi N. S .N, Kamran Jafri M., Naeem M., Alawadi E. A., Metwaly M. A. First level seismic microzonation map of Al-Madinah province, western Saudi Arabia using the geographic information system approach. Environ Earth Sci 2016, 75:251.

11. Papadimitriou A. G., Antoniou A. A., Bouckovalas G D. Marinos Pavlos G. Methodology for automated GIS-aided seismic microzonation studies. Computers and Geotechnics 2008, 35, 505-523.

12. QGIS.org, 2021. QGIS Geographic Information System. QGIS Association. http://www.qgis.org (accessed on 21 June 2021 )

13. Steiniger, S., Hunter, A.J.S., The 2012 free and open source GIS software map - A guide to facilitate research, development, and adoption. Comput. Environ. Urban Syst. 2013, 39:136-150, https://doi.org/10.1016/j.compenvurbsys.2012.10.003 
14. Quadrio B., Bramerini, F., Castenetto S., and Naso G. A New Step for Seismic Microzonation Studies in Italy: Standards for Data Storage and Representation. In Engineering Geology for Society and Territory - Volume 5, G. Lollino et al. (eds.). Springer International Publishing Switzerland 2015

15. UNDRR - United Nations Office for Disaster Risk Reduction. Strategic framework 2022-2025. Sendai Framework for Disaster Risk reduction for 2015-2030. https://www.undrr.org/publication/undrr-strategic-framework-2022-2025. Available online: URL (accessed on 24 May 2021). 